\title{
Lactic Acid Bacterial Vaginosis among Outpatients in Addis Ababa
}

\author{
Seblewongiel Ayenalem ${ }^{1}$, Lukman Yusuf ${ }^{2}$, Mogessie Ashenafi ${ }^{3}$
}

\begin{abstract}
Background: Bacterial vaginosis (BV) is a polymicrobial syndrome in which a decrease in vaginal acidity and concentration of lactobacilli is accompanied by an increase of other pathogenic micro-organisms. The distribution of lactic acid bacteria in vaginal environment of Ethiopian women has not been documented.

Objective:To assess the frequency of bacterial vaginosis in women visiting a gynecological clinic in Addis Ababa and to characterize the most common lactic acid bacteria isolated from vaginal fluid.

Methods: Vaginal samples from a total of 100 women aged between 18 and 60 years and visiting a gynecological clinic in Addis Ababa were collected between January and June, 2008 and analyzed for their microbial flora. Their Nugent score was determined microscopically and Lactic acid bacteria were isolated, characterized and their drug resistance determined.

Results: BV frequency among these study women was $32 \%$. Only $15 \%$ were symptomatic as detected by the presence of malodor or abnormal discharge. The majority (44\%) was in the age group of 18-30 years and less than a quarter of them had BV. It was also detected in about a third of women belonging to the two major religious denominations had $\mathrm{BV}$. The frequency of BV among pregnant women was low. The frequency of BV in women with prior abortion was slightly higher than 1/3. A total of 350 lactic acid bacterial isolates were obtained and $40 \%$ of them belonged to Lactococcus species. Lactobacillus, Leuconostoc, and Pediococcus were encountered at different frequencies. Resistance was seen against all drugs at various frequencies among the LAB (Lactic Acid Bacteria) isolates. Resistance of LAB to all antibiotics tested ranged between $20 \%$ and $42 \%$, and the least resistance was noted against vancomycin. All women who had been positive for bacterial vaginosis were accordingly treated.

Conclusion: Bacterial vaginosis may contribute to adverse reproductive outcomes. Prevalence of bacterial vaginosis in this study compares well with other African studies. The species richness and relative abundance of vaginal lactic acid bacteria in this study may be considered to design better probiotic products as bacterial replacement therapy. [Ethiop.
\end{abstract} J. Health Dev. 2010;24(3):198-204]

\section{Introduction}

The adult human vagina is a complex ecosystem containing an abundance of microorganism. The vagina and its unique microflora form a finely balanced ecosystem, with the vaginal environment controlling the presence of microbes and the microflora, in turn, controlling the vaginal environment (1). Vaginal microbial communities play a role in colonization resistance, protection against invasion by pathogens and dominance by potentially pathogenic species among the normal flora. Thus, perturbations of the vaginal community structure may predispose individuals to various infectious diseases (2).

Bacterial vaginosis is a polymicrobial syndrome in which a decrease in vaginal acidity and concentration of lactobacilli is accompanied by an increase of other pathogenic micro-organisms such as Gardnerella vaginalis and Mobiluncus spp. (3). According to Zhou et al., (1), lactobacilli have been thought to be the predominant members of normal post pubertal vaginal microflora. However, a diverse array of other bacteria such as Staphylococcus, Ureaplasma, Corynebacterium,
Streptococcus, Peptostreptococcus, Gardnerella, Bactericides, Mycoplasma, Enterrococcus, Escherichia, Veiloella, Bifidobacterium and Candida can be present but in much lower numbers. A general opinion is that species of the Lactobacillus acidophilus complex constitute most of the healthy vaginal Lactobacillus flora. However, a variety of other lactobacilli have been encountered (4).

In healthy vagina, lactobacilli produce hydrogen peroxide and lactic acid. These lower the vaginal $\mathrm{pH}$ to a level inhospitable to many other bacteria such as the anaerobic Gram-negative rods Bactericides and Prevotella, genital mycoplasmata, and Gardenerella vaginalis, Neisseria gonorrhoeae and Chlamydia trachomatis. A low $\mathrm{pH}$ has been shown to have direct microbicidal and virucidal effect (4). Lactobacilli can also adhere onto vaginal epithelial cells thus blocking the attachment of any pathogenic bacteria onto these cells. Lactobacilli are known to produce biosurfactants, bacteriocins and coaggregation molecules, all of which contribute to the maintenance of a healthy vaginal micro-environment (5).

\footnotetext{
${ }^{\text {T}}$ Department of Biology, Bahir Dar University. P O Box 79, Bahir Dar, Ethiopia;

${ }^{2}$ Department of Obstetrics and Gynecology, Faculty of Medicine, Addis Ababa University;

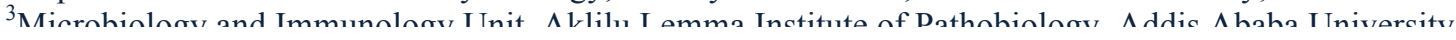


Hydrogen peroxide inhibits the growth of Bactericides, Gardnerella, Mobiluncus, Mycoplasma and other vaginal organisms also react with halide ions in the presence of vaginal peroxidase as part of the $\mathrm{H}_{2} \mathrm{O}_{2}$-halide peroxidase antibacterial system $(6,7)$. Various studies show that $\mathrm{H}_{2} \mathrm{O}_{2}$ producing lactobacilli strains are found in about $96 \%$ of women with normal vaginal microflora but only in about $6 \%$ of women with bacterial vaginosis suggesting its protective role against bacterial vaginosis and other sexually transmitted diseases $(8,9)$.

The microorganisms normally present in the human vagina play a key role in preventing successful colonization by undesirable organisms, including those responsible for bacterial vaginosis, yeast infections, sexually transmitted diseases and urinary tract infections (10). Moreover, epidemiologic studies have clearly indicated that abnormal vaginal microbial communities and lower genital tract infections were significantly associated with an increased risk of sexually transmitted diseases including HIV/AIDS (11).

Bacterial vaginosis (BV) is a clinical syndrome presenting with a malodorous vaginal discharge and increased vaginal $\mathrm{pH}$. Diagnosis has been made based on clinical Amsel criteria and direct Gram stain of vaginal secretions. Generally, factors such as frequency of sex, active sexual behavior (12), menstrual cycle (13) contraceptive use and douching (14) have been given as major reasons for the instability of vaginal flora in reproductive age group women. The treatment of bacterial vaginosis with metronidazole of $400 \mathrm{mg}$ or clindamycin of $300 \mathrm{mg}$ should be administered twice daily per os for 5 to 7 days with or without local treatment with gel or cream preparations. Pregnant women who are at risk of developing premature rupture of membranes and pre-term labour patients who actually have the infection, and or those who are to undergo pelvic and abdominopelvic operations are the beneficiaries of treatment schedules. Nevertheless, it is to be noted that relapses should be anticipated as these drugs are ineffective against Mycoplasma hominis and the continued presence of yet other unidentified microorganisms $(15,16,17)$.

In women of childbearing age, bacterial vaginosis (BV) is the most common cause of vaginitis. In BV, normal vaginal flora, consisting of hydrogen peroxide-producing lactobacilli, are replaced by Gardnerella vaginalis, Mycoplasma hominis, Mobiluncus species, and anaerobic gram-negative rods (18). Recombinant lactobacilli are engineered to express HIV-1 fusion inhibitor with potent neutralizing activity and this is believed to contribute to the development of a live microbial (topical) microbicide against HIV-1 infection (19).

The main aim of this study was to assess the prevalence of bacterial vaginosis in women visiting a gynecological clinic in Addis Ababa and to identify and characterize the most common Lactic acid bacteria isolated from vaginal fluid. Further more, the study assessed the distribution of drug resistance among the dominant lactic acid bacteria isolates from vaginal microflora.

\section{Methods}

A total of 100 women who were quasi randomly selected and aged between 18 and 60 years were considered in the study. These were outpatient clients visiting Monday, Wednesday and Friday Gynaecological and Obstetrical clinical services of a Higher Clinic in Addis Ababa from January 2008 to June 2008. The women were residents of Addis Ababa and information regarding demographic characteristics, medical, surgical, sexual and reproductive history was recorded. All the enrolled patients did not have an earlier established clinical and microbiological diagnosis of bacterial vaginosis. Those who did not give their consent or had and/or gave history suggestive of clinical signs and symptoms of urethritis, vulvovaginitis, cervicitis, endometritis and salpingitis were excluded from the study. All the patients who were found to have bacterial vaginosis were eventually treated for the infection by the gynaecologist; and the intervention was designed in such a way that it will not affect patient recruitment, specimen collection, data compilation and analysis.

\section{Specimen Collection}

A total of 100 vaginal specimens were collected from the patients. Sampling of the specimen was carried out by the gynecology and obstetrics specialist through insertion of a sterile cotton swabs into the vaginal lateral wall. The swab was rotated against the vaginal wall at the mid portion of the vault and was carefully removed. The samples were separately put in sterilized test tubes and transported to the microbiology laboratory of the Institute of Pathobiology, AAU within two hours.

\section{Determination of Nugent score}

The swab was first used for anaerobic culture preparation by streaking on the MRS agar plates. The same swab was used to prepare a smear on a glass slide for Gram staining. The microbiological evaluation of vaginal microflora pattern was made using Nugent scoring system (20), based on counting bacterial cell types on Gram stained slides of vaginal smears.

The smear was interpreted as normal (score 0-3) when the lactobacilli morphotype was present alone or in combination with very few Gardnerella morphotype (Small Gram-negative rod). When lactobacilli were found in low number and Gardnerella and Mobiluncus groups were seen in considerable large number. This was interpreted as intermediate (score of 4-6). When a more mixed flora, including not only the Gardnerella morphotype but also other Gram-negative and Grampositive bacteria, such as curved rods, Gram negative rods and Gram-positive cocci, are present and when the Lactobacillus morphotype was completely absent, the smear was interpreted as consistent with BV (score 7-10). (20). 
Number of bacteria between 1 and 30 per field of microscope was taken as approximate representative of bacteria in the whole field. The amounts of different bacterial morphotypes were then transformed to intervals in accordance with Nugent scoring system. Finally, the points achieved from the amount of different bacterial morphotypes were added together.

\section{Isolation and Identification of Lactic Acid Bacteria (LAB)}

Lactic acid bacteria were isolated on MRS (de Mann Rogosa Sharp) agar plates after swabbing on the plates and incubating using anaerobic jar at $37^{\circ} \mathrm{C}$ for $48-72$ hours. Five colonies were randomly selected from each MRS agar plate. The colonies were isolated and purified using Brain Heart Infusion (BHI) broth. The isolates were grouped as lactic acid bacteria based on their Gram reaction, colony morphology, catalase reaction and homofermentative/heterofermentative test in MRS broth containing $5 \%$ glucose.

\section{Antibiotic Susceptibility Test}

The antimicrobial activities of the isolates were quantified by disc diffusion method as suggested by Bauer et al., (21). A well-isolated colony was selected from MRS agar plate and transferred into a tube containing sterile BHI broth. The inoculated broth was incubated at $37^{\circ} \mathrm{C}$ for 24 hours. Broth culture was swabbed on the entire dried surface of a Mueller-Hinton agar plate. Eight antibiotic discs consisting of Ampicillin (10mg), Clindamycin (2mg), Gentamycin (10mg), Kanamycin (30mg), Methicillin (5mg), Penicillin (10 unit), Streptomycin (10mg) and Vancomycin (30mg) were placed on the surface of the agar plate using disk dispenser and incubated for 24 hours at $37^{\circ} \mathrm{C}$. The diameter of the zones of complete inhibition was measured to the nearest whole number in millimeter, using transparent ruler. Intermediate readings were considered sensitive for the purpose of interpretation.

\section{Ethical Consideration}

Ethical clearance was obtained from ethical Clearance Committee of Biology Department in AAU. The subjects were included in the study after the purpose of the study was clearly explained to all subjects and they were included in the study after they consented. Any patient positive for $\mathrm{BV}$ was treated by the physician.

\section{Results}

The microbiological evaluation of vaginal microflora pattern was made using Nugent scoring system that was based on counting the bacterial cell types on the Gram stained slides of vaginal smears (Table 1). According to this study large Gram-positive bacilli were dominantly present in $42 \%$ of the women. The typical appearance of the organisms identified as having the Lactobacillus morphotype was evident for the absence of bacterial vaginosis and generally interpreted as normal flora (score 0-3).

In $26 \%$ of the women, two or three bacterial morphotypes were evident. Stains showing the presence of few Lactobacillus and many Gram-negative morphotypes (Gardnerella and/or Mobiluncus morphotype) were interpreted as intermediate flora (score 4-6).

Thirty two percent of the women in relation to Table 1 showed complete absence or low presence of Lactobacillus morphotype and a smear consistent with BV (score 7-10). The flora in this group of women was mainly composed of small Gram-negative organisms of the Gardnerella morphotype and curved Gram-negative rods (Mobiluncus morphotype).

LAB were isolated randomly from specimen cultures of 70 women (Table 3 ). Thirty women did not have genital cultures due to cases of either contamination or absence of growth. A total of 350 randomly picked colonies were purified and analyzed. Gram positive, catalase negative, cocci or rod shaped isolates which formed single, paired, tetrad or long chain colony arrangements were considered to belong to the lactic acid bacteria. These were classified based on their colony morphology and fermentation test results to one of the following four genera: Lactobacillus, Lactococcus, Leuconostoc, and Pediococcus.

The resistance pattern of the isolates against different antibiotics is presented in Table 4. It was found out that the resistance of LAB to all antibiotics was in the range of $20-40 \%$ and the least resistance was noted against vancomycin.

\section{Discussion}

Understanding the structure of normal vaginal communities is very important for at least two reasons. First, some of these microbes may have physiological functions that directly affect the health of women. They play a role in colonization resistance and providing protection against invasion by pathogens. Second, change of the community structure of vaginal ecosystem may predispose individuals to various infectious diseases (1, 2).

In this study, BV frequency in the study population was $32 \%$. Although the sample size was not large enough to make reasonable comparisons, observations in this study variably compare with the studies that have specifically assessed BV prevalence among African settings. Demba et al. (22) reported prevalence of $47.6 \%$ in the Gambia, $20-23 \%$ in Burkina Faso and Malawi, 37\% in Tanzania and $49 \%$ in Kenya populations. BV appears to be more common in Africa than in industrialized countries (23, 24). The reasons for these apparent differences are not still fully understood. Researchers have suggested, as a possible explanation, that levels of education and other socio-economic factors increased the rate of BV in Africa $(13,22)$. 
Table 1: Scoring Vaginal Gram's Stain for Bacterial Vaginosis (Nugent et al, 1991)

\begin{tabular}{lcccccc}
\hline \multicolumn{1}{c}{ Scale } & $\begin{array}{c}\text { Lactobacillu } \\
\text { s }\end{array}$ & Score & Gardnerella & Score & Mobiluncus & Score \\
\hline $4+=>30$ organism/ field & $4+$ & 0 & $4+$ & 4 & $4+$ & 2 \\
$3+=5-30$ organism/ field & $3+$ & 1 & $3+$ & 3 & $3+$ & 2 \\
$2+=1-4$ organism/ field & $2+$ & 2 & $2+$ & 2 & $2+$ & 1 \\
0 or $1+=<1$ organism/ & 0 & 4 & 0 & 0 & 0 & 0 \\
field & & & & & & \\
\hline
\end{tabular}

Of the women who were included in the study, only $15 \%$ were clinically suspected to have bacterial vaginosis. This fact was detected by the presence of fishy malodor or abnormal discharge as confirmed by the physician during clinical diagnosis. In other studies, women with $\mathrm{BV}$ often reported no signs or symptoms at all and up to $50 \%$ of women were asymptomatic (2). These asymptomatic women are less likely to seek treatment and thus are more likely to acquire other serious STDs including HIV/AIDS $(9,23)$. Different studies reported that changes in structure and composition of vaginal ecosystem are influenced by age, time in menstrual cycle, pregnancy, infections, methods of birth control, frequency of sexual activities as well as number of sexual partners, various habits and practices such as douching and $\mathrm{pH}$ of the vaginal fluid (10).

Due to the small sample size, we could not associate BV with a given age group although it has higher frequency among the age group of 31-40 years. Some researchers have previously reported that $\mathrm{BV}$ is more common among younger women (25), while others observed that the risk for $\mathrm{BV}$ increased with age (2).The finding in our setup was quite similar with the latter observation.

It may be inappropriate to compare the frequency of BV among religious dominations because of lack of comparability in the number of samples. However, it could be said that about a third of the patients in both groups had BV (Table 2). A study in India showed BV frequency was higher among the Christian population (26). Certain risk factors such as genital hygiene practices that are known to be associated with BV may vary with religion (25). Similarly we had a low number of unmarried patients to make a reasonable comparison, although a third of the patients in both marital status groups had BV. It is worth noting, however, that $24 \%$ of the married or single patients had asymptomatic BV.

The frequency of BV among pregnant women was low (Table 2). On the other hand, among the 89 non-pregnant women, a total of 55 had intermediate vaginal flora or $\mathrm{BV}$. In different studies pregnant women with $\mathrm{BV}$ are considered to be at increased risk for having preterm birth, infants with low birth weight and premature rupture of the membranes $(15,23)$. Therefore, screening pregnant women for bacterial vaginosis may help to identify a group at higher risk for preterm birth and to offer adequate treatment (27).
The majority of women $(81 \%)$ had no abortion history and about $1 / 3$ of them had BV (Table 2). Although the number was low, the frequency of BV in women with prior abortion was slightly higher than one third. A growing body of literature showed an increased risk of spontaneous abortion among pregnant women with BV $(5,18)$. Moreover, studies found significant associations between bacterial vaginosis and the use of contraceptive (28). Only 11 of the patients in this study used any one of the contraceptive methods. The frequency of use of any of the contraceptive methods was $<4 \%$. Among the 89 non-users, more than half had either intermediate vaginal flora or BV. In our study the majority of contraceptive users had dominant intermediate flora and BV was seen only in two of the four recorded oral contraceptive users. Since, bacterial vaginosis is common among women in the reproductive age group who are also the most likely contraceptive users, any association between BV and contraceptive use could be the result of the age structure of the women (18).

The most predominant isolates were long chained, coccishaped homofermentative lactococci which comprised $40 \%$ of the 350 isolates. As to Todorov et al (29) stated, Lactococcus lactis, isolated from vaginal secretions, produced a bacteriocin that caused death to Gram positive and Gram negative bacteria. Lactobacilli constituted $29 \%$ of the isolates. Of these lactobacilli, $84 \%$ were homofermentative and the rest were heterofermentative. The dominance by homofermentative lactobacilli was indicative of the production of more acid from fermentable sugars which may come from glycogen in the vaginal environment. Pediococci made up of $23 \%$ of the total LAB colonies. Finally, colonies which were cocci but showed hetrofermentative nature were identified as Leucnostoc and made up $8 \%$ of the total LAB.

A considerably different proportion of LAB isolates were encountered in this study. The species richness and relative abundance of lactic acid bacteria in vagina is documented $(23,30)$. According to these studies, though a large number of lactic acid bacteria colonize the vagina, their genera and species distributions may be different in women of geographically separated communities. Moreover, the knowledge of species richness and relative abundance of vaginal lactic acid bacteria may lead to the design of better probiotic products as bacterial replacement therapy. 
Table 2: Prevalence of BV among outpatients in Addis Ababa (Jan., 2008-July, 2008) Socio-demographic and Clinical Status of Women Using Nugent's Criteria

\begin{tabular}{|c|c|c|c|c|c|}
\hline & & Total & Normal & Intermediate & BV \\
\hline \multirow[t]{4}{*}{ Age group } & $18-30$ & 44 & 23 & 11 & 10 \\
\hline & $31-40$ & 27 & 10 & 3 & 14 \\
\hline & $41-50$ & 21 & 8 & 6 & 7 \\
\hline & $>50$ & 8 & 1 & 6 & 1 \\
\hline \multirow[t]{2}{*}{ Pregnancy } & Pregnant & 11 & 6 & 3 & 2 \\
\hline & Non-pregnant & 89 & 36 & 23 & 30 \\
\hline \multirow[t]{2}{*}{ Abortion } & Previous Abortion & 19 & 6 & 6 & 7 \\
\hline & Non abortion & 81 & 36 & 20 & 25 \\
\hline \multirow[t]{4}{*}{ Contraceptive usage } & Loop & 4 & 1 & 3 & 0 \\
\hline & Injection & 3 & 1 & 2 & 0 \\
\hline & Pills & 4 & 0 & 2 & 2 \\
\hline & Non-user & 89 & 40 & 19 & 30 \\
\hline \multirow[t]{2}{*}{ Religious denomination } & Christian & 62 & 29 & 12 & 21 \\
\hline & Muslim & 38 & 13 & 14 & 11 \\
\hline \multirow[t]{2}{*}{ Marital status } & Married & 93 & 38 & 24 & 31 \\
\hline & Single & 7 & 4 & 1 & 2 \\
\hline \multirow[t]{2}{*}{ Clinical case } & Asymptomatic & 85 & 40 & 21 & 24 \\
\hline & Symptomatic & 15 & 2 & 5 & 8 \\
\hline
\end{tabular}

Table 3: Microscopic characteristics, $\mathrm{KOH}$ and Catalase Test Results of Lactic Acid Bacteria Isolated from Women's Vaginal Fluid in Addis Ababa (Jan., 2008-July 2008)

\begin{tabular}{|c|c|c|c|c|c|c|}
\hline LAB Isolated & $\begin{array}{l}\text { Colony } \\
\text { morphology }\end{array}$ & $\begin{array}{l}\text { Colony } \\
\text { arrangement }\end{array}$ & Fermentation Test & $\mathrm{KOH}$ test & $\begin{array}{l}\text { Catalase } \\
\text { test }\end{array}$ & $\begin{array}{l}\text { Isolates } \\
(350)\end{array}$ \\
\hline Lactococci & Cocci & Long Chain & Homofermentative & Positive & Negative & $\begin{array}{l}140 \\
(40 \%)\end{array}$ \\
\hline & Rod & Single & $\begin{array}{l}84 \% \text { Homo- } 20 \% \\
\text { Hetro-fermentative }\end{array}$ & Positive & Negative & $\begin{array}{l}100 \\
(28.57 \%)\end{array}$ \\
\hline Pediococci & Cocci & Pair or Tetrad & Homofermentative & & & $\begin{array}{l}82 \\
(23.43 \%)\end{array}$ \\
\hline Luconostoc & Cocci & $\begin{array}{l}\text { Pair or Short } \\
\text { chain }\end{array}$ & Hetrofermentative & $\begin{array}{l}\text { Positive } \\
\text { Positive }\end{array}$ & $\begin{array}{l}\text { Negative } \\
\text { Negative }\end{array}$ & $28(8 \%)$ \\
\hline
\end{tabular}

Table 4: The Antimicrobial Activity of LAB Isolates from Women's Vaginal Fluid in Addis Ababa (Jan., 2008July 2008)

\begin{tabular}{lllllllll} 
& Amp & Cli & Gen & Kan & Met & Pen & Str & Van \\
\hline Resistant & $16(26.7 \%)$ & $25(41.7 \%)$ & $16(26.7 \%)$ & $18(30 \%)$ & $24(40 \%)$ & $20(33.3 \%)$ & $22(36.7 \%)$ & $12(20 \%)$ \\
Intermediate & $12(20 \%)$ & $5(8.3 \%)$ & $2(3.3 \%)$ & 0 & 0 & $34(56.7 \%)$ & 0 & 0 \\
Sensitive & $32(53.3 \%)$ & $30(50 \%)$ & $42(70 \%)$ & $42(70 \%)$ & $36(60 \%)$ & $6(10 \%)$ & $38(63.3 \%)$ & $48(80 \%)$ \\
\hline
\end{tabular}

Where: Amp, Ampicillin; Cli, Clindamycin; Gen, Gentamycin; Kan, Kanamycin; Met, Methicillin; Pen, Penicillin; Str, Streptomycin; Van, Vancomycin

Generally speaking, an inverse relationship was observed between the presence of Lactobacillus morphotype and Gardnerella morphotype. When the Lactobacillus morphotype was dominant, the Gardnerella morphotype was usually absent. When the Gardnerella morphotype was dominant the quantity of the Lactobacillus morphotype was generally diminished. As per the result of this study, a comparison of vaginal micro-flora isolates with Nugent's score showed significant positive associations with $\mathrm{BV}$ and a significant negative association with the presence of lactobacilli or vice versa. These findings generally coincide with findings in other studies $(20,22)$, since the method employed for the Nugent's score is based on the observation of BVassociated bacterial morphotypes.

Resistance was seen against all drugs at various frequencies among the LAB isolates. In general, it can be said that resistance of $\mathrm{LAB}$ to all antibiotics tested ranged between $20 \%$ and $42 \%$, and the least resistance was noted against vancomycin. It is very important to know about the antimicrobial susceptibility or resistance of LAB isolated from human vagina to predict the behavior of an applied probiotic or to consider the application of probiotic strains, along with antibiotics, in women with bacterial vaginosis to allow the restoration of the normal genital flora (23). For example, a bacteriocin-producing Lactococcus lactis was effective as a probiotic if taken with specific antibiotics and not with anti-inflammatory drugs and spermicides (29). In this regard, the performance of antimicrobial susceptibility testing of vaginal specimen may be considered as an effective guide for specific antimicrobial therapy for women with genital tract infections including BV (31).

Fthinn I Hoalth Dov, Tn1ח.74(2) 
Over $41.7 \%$ of our isolates were resistant to Clindamycin. This result has interesting meaning because Clindamycin is one of the most commonly prescribed antibiotics for the treatment of bacterial vaginosis (32). Thus, resistance of vaginal LAB against Clindamycin could be considered as an advantage because the LAB would function as resident probiotics even after treatment for BV.

\section{References}

1. Zhou X, Bent S, Schneider M, Davis C, Islam M, Forney L. Characterization of vaginal microbial communities in adult healthy women using cultivation-independent methods. Microbiol 2003; 150: 2465-2573.

2. Morris M, Nicoll A, Simms L, Wilson J, Catchpole M. . Bacterial vaginosis: A public health review. Int J Obstet Gynecl 2001; 108: 439-450.

3. Bradshaw S, Morton A, Garland M, Morris B. Moss L, Fairley K. Higher-Risk behavioral practices associated with bacterial vaginosis compared with vaginal candidiasis. Obstet Gynecol 2005; 106:105114.

4. Vasquez A, Jakobsson T, Ahrne S, Forsum U, Molin G. Vaginal Lactobacillus flora of healthy Swedish women. J Clin Microbiol 2000; 28: 2746-2749.

5. Wilks M, Wiggins R, Whiley A, Hennessy E, Warwick S, Porter H, Corfield A, Miler M. Identification and hydrogen peroxide production of vaginal lactobacilli from pregnant women at high risk of preterm birth and relation with outcome. $J$ Clin Microbiol 2004; 42:713-714.

6. Hawes S, Hillier S, Benedetti J, Stevens C, Koutky L, Wolner-Hassen P. Hydrogen peroxide-producing lactobacilli and acquisition of vaginal infections. $J$ Infect Dis 1996; 174:1058-1063.

7. Hillier S, Krohn M, Rabe L, Klebanoff S, Eschenbach D. The normal vaginal flora, H2O2producing lactobacilli, and bacterial vaginosis in pregnant women. Clin Infect Dis 1993; 16: 273-281.

8. Eschenbach D, Davick P, Williams B, Klebanoff S, Young-Smith K, Critchlow C. Prevalence of hydrogen peroxide-producing Lactobacillus species in normal women and women with bacterial vaginosis. J Clin Microbiol 1989; 27:251-256.

9. Taha E, Hoover R, Dallabetta A, Kumwenda I, Mtimavalye L, Yang L, Liomba N, Broadhead L, Chiphangwi D, Miotti G. Bacterial vaginiosis and disturbances of vaginal flora: association with increased acquisition of HIV. AIDS 1998; 12:16991706.

10. Vitali B, Pugliese C, Biagi E, Candela M, Turroni S, Bellen G, Donders G Brigidi P. Dynamics of Vaginal Bacterial Communities in Women Developing Bacterial Vaginosis, Candidiasis, or No Infection, Analyzed by PCR-Denaturing Gradient Gel Electrophoresis and Real-Time PCR. Appl Environ Microbiol 2007; 73: 5731-5741.

11. Dumestre K, Wenthold C, Hagensee M, Martin D. Vaginal swabs versus lavage for detection of
Bacterial vaginosis may contribute to adverse reproductive outcomes. The role of $\mathrm{BV}$ as an independent risk factor for pelvic inflammatory disease, infertility, preterm delivery and miscarriage is yet to be shown. The use of probiotic LAB against BV may probably contribute to minimize the public health profile of women at risk of reproductive morbidity and mortality.

Trichomonas vaginalis and bacterial vaginosis among HIV-positive women. Sex Transm Dis 2005; 32(4):227-230.

12. Alesna E, Viduya M, Manalastas A, Baello B, Cardano R, Borromeo R, Vilma C, Tupasi T.Multiple Sexual Partners: Risk Factor for Bacterial Vaginosis. Phil J Microbiol Infect Dis 1996; 25:1-3.

13. Morison L, Ekpo G, West B, Demba E, Mayaud P, Coleman R, Bailey R, Walraven G. Bacterial vaginosis in relation to menstrual cycle, menstrual protection method, and sexual intercourse in rural Gambian women. Sex Transm Infect 2005; 81:242247.

14. Bhalla P, Chawla R, Garg, S, Singh M, Raina U, Bhalla R, Sodh P. Prevalence of bacterial vaginosis among women in Delhi, India. Indian $J$ Med Res 2002; 125:167-172.

15. Ison CA, Taylor RFH, Link C, Buckett P, Harris JRW, Easmon CSF. Local treatment for bacterial vaginosis. $B M J$ 1987; 295:886-887.

16. Bradshaw CS, Morton AN, Hocking J, Garland SM, Morris MB, Moss LM, Horvath LB, Kuzevska I, Fairley CK. High recurrence rates of bacterial vaginosis over the course of 12 months after oral metronidazole therapy and factors associated with recurrence. J Infect Dis 2006: 193:1478-86.

17. Senok AC, Verstraelen H, Temmerman M, Botta GA. Probiotics for the treatment of bacterial vaginosis. Cochrane Database Syst 2009; Rev (4): CD006289.

18. Sobel J. Bacterial vaginosis. Ann Rev Med 2000; 51:349-356.

19. Pusch, O, Kalyanaraman R, Tucker L, Wells J, Ramratnam B, Boden D. An anti-HIV microbicide engineered in commensal bacteria: secretion of HIV1 fusion inhibitors by lactobacilli. AIDS 2006: 20:1917-1922.

20. Nugent R, Krohn M, Hillier S. Reliability of diagnosing bacterial vaginosis is improved by a standardized method of gram stain interpretation. $J$ Clin Microbiol 1991;29:297-301.

21. Bauer AW, Kirby WM, Sherris JC, Turck M. Antibiotic susceptibility testing by a standardized single disk method. Am J Clin Pathol 1966; 45:4936.

22. Demba E, Morison L, Loeff M, Awasana A, Gooding E, Bailey R, Mayaud P, West B. Bacterial vaginosis, vaginal flora patterns and vaginal hygiene practices in patients presenting with vaginal discharge syndrome in The Gambia, West Africa. Infect Dis 2005; 5:12-20.

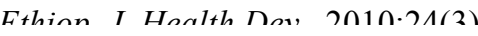


23. Senok A, Verstraelen H, Temmerman M Botta G. Probiotics for the treatment of bacterial vaginosis. Cochrane Database of Syst Rev 2009; Oct7;4:CD006289.

24. Forsum U, Hallén A, Larsson P. Bacterial vaginosis a laboratory and clinical diagnostics enigma. APMIS 2005; 113:153-161.

25. Bukusi E, Cohen C, Meier A, Waiyaki P, Nguti R, Njeri J, Homless K. Bacterial Vaginosis: Risk factors among Kenyan Women and their Male Partners. Sex Transm Dis 2006; 33: 361-367.

26. Madhivanan P, Krupp K, Chandrasekaran V, Karat C, Arun A, Cohen C, Reingold A, Kalusner J. Prevalence and Correlates of Bacterial Vaginosis among Young Women of Reproductive Age in Mysore, India. Indian J. Med Microbiol 2008; 26(2): 132-137.

27. Nelson D, Macones G. Bacterial Vaginosis in Pregnancy: Current Findings and Future Directions. Epidemiol Rev 2002; 24:102-108.
28. Moi H. Prevalence of bacterial vaginosis and its association with genital infections, inflammation, and contraceptive methods in women attending sexually transmitted disease and primary health clinics. Int. J. STD AIDS 1990; 1:86-94.

29. Todorov SD, Botes M, Danova ST, Dicks LM. Probiotic properties of Lactococcus lactis ssp. lactis HV219, isolated from human vaginal secretions. $J$ Appl Microbiol 2007; 103:629-39.

30. Jin L, Tao L, Pavlova S, Kiwanuka N, Namukwaya Z, Saberbein B,Wawer M. Species diversity and relative abundance of vaginal lactic acid bacteria from women in Uganda and Korea. $J$ Appl Microbiol 2007; 102(4): 1107-1115.

31. Reid G, Jass J, Sebulsky T John K. Potential Uses of Probiotics in Clinical Practice. Clin Microbiol Rev 2003; 16: 658-672.

32. Ocana V, Silva C, Nader-Macías M. Antibiotic Susceptibility of potentially probiotic vaginal Lactobacilli. Infect Dis Obstet Gyneco 2006; Art ID 18182: 1-6. 